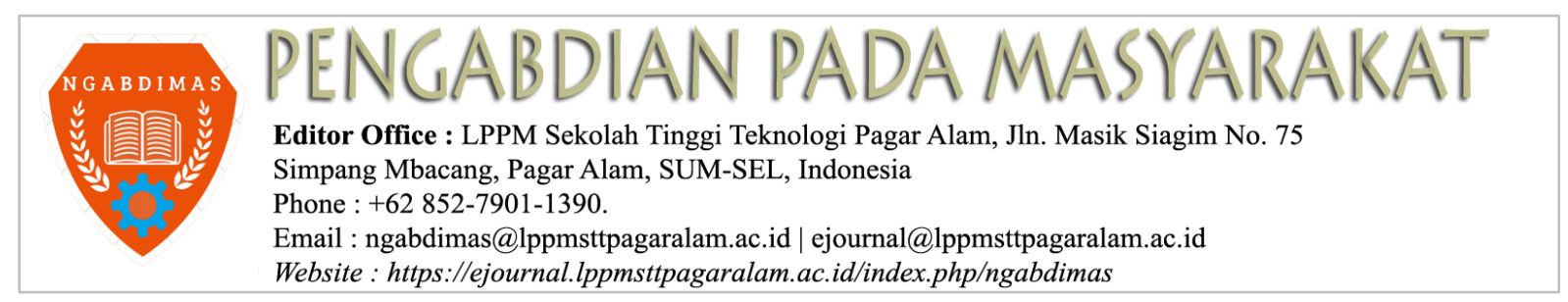

\title{
Pelatihan Pembuatan Blog Bagi Guru Ma Ponpes Darul Mutaqin Kota Pagar Alam
}

\author{
Buhori Muslim \\ Program Studi Teknik Informatika; Sekolah Tinggi Teknologi Pagaralam (STTP) \\ Jl. M. Siagim No.75 Kel. Karang Dalo, Dempo Tengah, Kota Pagar Alam \\ Telp/Fax: (0730) 621916 \\ e-mail: buhoristtp@gmail.com
}

\begin{abstract}
Abstrak
Pengabdian kepada masyarakat merupakan kewajiban tri dharma bagi civitas akademika STTP. Pelatihan pembuatan Blog bagi Guru MA Ponpes Darul Muttaqien ini merupakan kesadaran terhadap pelaksanaan tri dharma tersebut, kegiatan ini merupakan rangkaian dari Kuliah kerja nyata, pembuatan blog dari hasil observasi dianggap penting untuk menjadi awal MA Darul Muttaqien mengikuti perkembangan industry 4.0 yang serba digital dimana tujuan akhirnya adalah sistem pembelajaran mengarah kepada multimedia didukung sistem online untuk kelancaran proses belajar. Metode yang digunakan menganalisa masalah menggunakan pre dan post tes sehingga langsung diketahui pemahaman peserta pelatihan terhadap blog dan sistem digital, hasilnya cukup sigifikan dari 10 pertanyaan materi yang diberikan saat pre tes peserta tidak mampu memperoleh nilai 10, nilai paling tinggi 9 hanya ada 3\% dari 15 peserta dan saat pos tes terdapat 4,5\% yang memperoleh nilai 10, dan 6\% yang memperoleh nilai 9. Sehingga pelatihan penting untuk meningkatkan pemahaman peserta pelatihan pembuatan Blog Pembelajaran.
\end{abstract}

Kata kunci-Pengabdian, STTP, Guru, Blog, Pembelajaran, Materi.

\section{PENDAHULUAN}

Perkembangang teknologi dan sistem informasi sangat pesat, hal ini didukung isu industrialisasi 4.0 yang tidak terbendung mengarah pada sistem yang serba digital, serba elektronik yang mempergunakan kecerdasan buatan, perkembangan ini juga merambah bidang pendidikan, sistem pendidikan saat ini juga mengikuti perkembangan ini, sistem pendidikan konvensional di yakini pakar mengikuti mempergunakan sarana serba multimedia, serba digital dan serba electronic sehingga belakangan muncul home schoolling, sistem pembelajaran e-learning dan sebagainya. Pada Madrasah Aliyah (MA) Darul Muttaqin sistem pendidikan masih konvensional $100 \%$ pembelajaran siswa masih bertemu dan bertatap muka dengan Guru dalam kelas, dalam perkembangannya unsur Pimpinan MA sangat menyadari perubahan sistem pendidikan pada saat yang akan datang, sehingga dengan adanya program Kuliah kerja nyata (KKN) atau Pengabdian kepada masyarakat (PKM) yang dilakukan Mahasiswa dan Dosen Sekolah Tinggi Teknologi Pagaralam (STTP) Periode Tahun 2018, maka MA Darul Muttaqien bekerja sama dengan Peserta KKN \& Pengabdian melaksanakan kegiatan Pelatihan pembuatan blog pembelajaran bagi guru MA Darul Muttaqin.

Berdasarkan observasi pelatihan pembuatan blog sangat penting dan menjadi awal untuk para guru memahami teknologi, yang mana sebagian besar guru belum terlalu baik pemahamannya terhadap teknologi dan sistem informasi blogging atau website, diharapkan pelatihan ini menjadi pemicu guru untuk mempelajari multimedia dan website sistem pembelajaran lebih komprehenshif, Pembelajaran mempergunakan pendukung blog (website) terbukti membantu meningkatkan pemahaman dan nilai siswa peserta didik [2], lebih lanjut sistem pembelajaran mempergunakan saran website (e-learning) dan multimedia dapat meningkatkan minat dan prestasi siswa [3][6][13] 
selain itu Muslim, 2017 berpendapat bahwa perkembangan sarana kedepan mengarah pada sistem dan teknologi informasi [2][6][14], sehingga bila institusi pendidikan dan guru tidak mengadopsi dan mengikuti perkembangan teknologi dan sistem informasi pendidikan yang baru sangat diyakini akan terpuruk, yang mana menurut Muslim \& Prasetio [15], saat ini sekolah maju di Kota-kota besar Penerimaan dan Tes masuk sekolah sudah mempergunakan sistem online [15], jelas ini membuat sekolah yang masih mempertahankan cara lama akan kehilangan para peminatnya.

\section{METODE}

Pada pelaksanaan pengabdian (PKM) ini untuk memahami fenomena yang dihadapi daerah binaan atau tempat pengabdian terlebih dahulu dilakukan pengamatan dan menampung aspirasi dan permasalah oleh tim observasi lembaga penelitian dan pengabdian kepada masyarakat (LPPM) Sekolah Tinggi Teknologi Pagaralam (STTP), nantinya ditemukan kesimpulan yang akan menjadi bahan program kegiatan bagi para peserta KKN dan pengabdi pada saat datang ditempat pengabdian, sehingga kegiatan yang dilakukan akan sesuai dan tepat sasaran. Tetapi agar program kerja lebih baik lagi peserta pengabdian juga bisa melakukan observasi sendiri pada saat pelaksanaan pengabdiannya "Pelatihan pembuatan blog bagi guru MA Darul Muttaqin Kota Pagar Alam" ini merupakan salah satu masalah yang ditemukan dan diselesaikan pengabdi didaerah pengabdian Kecamatan Dempo Selatan Kota Pagar Alam, yang mana agar pelatihan berjalan baik dilakukan dengan Metode Pre dan Pos tes terhadap peserta pelatihan.

\subsection{Teknologi Informasi}

Teknologi Informasi berasal dari kata Information Technology, berdasarkan Kamus Advanced Leaner's Dictionary of Current English (1974) adalah penerapan pengetahuan secara sistematis pada tugas praktis dalam suatu industri. Senada definisi itu (Muslim, 2017) mengatakan Teknologi diartikan pelaksanaan ilmu, sinonim dengan ilmu terapan [3][10]. Kata Informasi pada Oxford Advanced Learners's Dictionary of Current English (1980: 437), diartikan sebagai sesuatu yang diberitahukan, pengetahuan dan berita. Sedang pada Ilmu Informasi kata Informasi, pengetahuan dan berita dibedakan. Menurut Teskey (Pendit,1992) data adalah hasil observasi langsung terhadap suatu kejadian, merupakan perlambangan yang mewakili objek atau konsep pada dunia nyata, dilengkapi dengan nilai tertentu; Informasi adalah kumpulan data yang terstruktur [2], disampaikan seseorang pada orang lain. Sedangkan berita menurut Arifin adalah informasi yang menarik, penting dan belum pernah didengar. Informasi merupakan sarana baku untuk menunjang dan meningkatkan kegiatan bidang Ilmu Pengetahuan, kebudayaan, dan teknologi [12]. Pengetahuan adalah sesuatu yang digunakan manusia untuk memahami dunia, yang dapat diubah berdasarkan informasi diterima. Pada jurnal ini informasi secara singkat diartikan sebagai segala data, fakta dan pengetahuan yang disampaikan kepada orang lain melalui berbagai media, dalam bentuk tekstual, gambar, maupun suara. Teknologi informasi merupakan sebuah istilah baru merupakan terjemahan dari Information Technology bagi kebanyakan orang teknologi informasi merupakan sinonim dari Teknologi Baru, karena karena kaitannya yang erat dengan mesin microprosesor, seperti mikro-komputer, alat-alat yang bekerja secara otomatis, seperti alat pengolah kata, dan lain sebagainya . Pengertian Teknologi Informasi berdasarkan British Advisory Council for Applied Research and Development (Zorkoczy, 1990). adalah meliputi bidang ilmu pengetahuan, teknologi dan perekayasaan serta teknik pengelolaan yang digunakan pada penanganan dan pengolahan informasi, penerapan bidang dan teknik tersebut, komputer dan interaksinya dengan manusia dan mesin, masalah sosial ekonomi serta budaya yang berkaitan. Memang banyak definisi tentang Teknologi Informasi, sehingga dalam "Macmillan Dictionary of Personal Computing and Communication" terdapat empat halaman yang menjelaskan tentang Teknologi Informasi. 


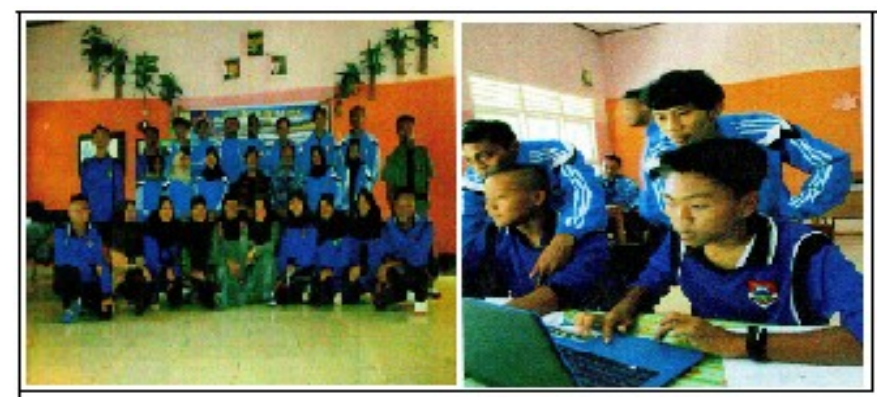

\subsection{Pembelajaran sistem blog}

Gambar 1. Kegiatan Pengabdian [1]

Pembelajaran menjadi lebih menarik, pembelajaran berbasis internet yang salah satu pengaplikasiannya berbentuk blog. Pemilihan blog sebagai media pembelajaran didasarkan atas beberapa faktor: (1). Blog populer karena relatif murah pengelolaannya, mudah untuk mengembangkan \& mudah digunakan; (2). Blog mudah digunakan untuk memberikan pekerjaan rumah pada siswa, di mana tiap siswa secara mandiri mengerjakan tugas masing-masing; (3). Blog memungkinkan user untuk mempublikasikan posting yang diurutkan atas kronologis terbalik (posting baru paling atas); 4). Tugas individu dapat dialokasikan guru atau dinegosiasikan dalam kelompok; 5). Bisa ditambahkan teks, gambar grafis, link informasi dengan situs lain, dan data lainnya; dan (6). Penulis dapat melakukan editing pada post setiap saat dan memungkinkan pembaca untuk meninggalkan komentar untuk posting asli dan saling berkomentar satu sama lain. Karakteristik ini memungkinkan peserta didik melalukan komunikasi dengan sumber ilmu secara lebih luas jika dibandingkan dengan hanya menggunakan media konvensional [12] Atas dasar pemikiran itu, dipandang perlu mengembangkan media pembelajaran berbasis blog sebagai media penyampai pesan dalam pembelajaran yang dapat dipelajari secara mandiri untuk mengatasi salah satu permasalahan mengajar [11]. Posisi blog yang dikembangkan disini hanya bersifat web centric course atau penggunaan internet yang memadukan antara belajar jarak jauh dan tatap muka (konvensional) [14].

\section{3. Sistem Pembelajaran}

Bahan ajar merupakan seperangkat materi yang disusun secara sistematis sehingga tercipta lingkungan/suasana yang memungkinkan peserta didik untuk belajar [6]. Bahan ajar berkualitas tinggi dapat berkontribusi secara substansial terhadap kualitas pengalaman belajar siswa dan outcome siswa [10]. Senada dengan pernyataan di atas, Warpala (2011) menyatakan bahan ajar adalah segala bentuk bahan yang digunakan untuk membantu guru/instruktur dalam melaksanakan kegiatan belajar mengajar di kelas. Bahan yang dimaksud bisa berupa bahan tertulis maupun bahan tidak tertulis. Berdasarkan media yang digunakan, bahan ajar dapat dikelompokkan menjadi lima kategori, yaitu: 1) bahan ajar audio seperti manusia, rekaman suara, radio; 2) bahan ajar cetak seperti buku, koran, majalah, poster; 3) bahan ajar visual seperti poster, foto, gambar; 4) bahan ajar audio-visual seperti film, video; 5) bahan ajar berbasis komputer seperti bahan ajar berbasis komputer, computer assisted instruction. Gerlach \& Ely dalam (Arsyad, 2009) mengatakan bahwa media apabila dipahami secara garis besar adalah manusia, materi atau kejadian yang membangun kondisi yang membuat siswa mampu memperoleh pengetahuan, keterampilan dan sikap. Dalam pengertian ini, guru, orang tua siswa, buku teks, lingkungan bermain, dan lingkungan sekolah merupakan media. Secara lebih khusus, pengertian media dalam proses belajar mengajar cenderung diartikan sebagai alat-alat grafis, fotografis, atau elektronis untuk menangkap, memproses, dan menyusun kembali informasi visual atau verbal. Beberapa pengertian media di atas, Association of Education and Communication Technology (AECT) [11] membatasi media sebagai segala bentuk dan saluran yang digunakan orang untuk menyalurkan informasi. Pendapat lain diberikan oleh Gagne [11] menyatakan bahwa media adalah berbagai jenis komponen dalam lingkungan siswa yang dapat merangsangnya untuk belajar. Pendapat Gagne diperkuat oleh Briggs [11] yang berpendapat bahwa media segala alat fisik yang dapat menyajikan pesan serta merangsang siswa untuk belajar [14].

\subsection{Penyelesaian Masalah}


Berdasarkan fenomena (masalah) yang dikemukakan dan alur penyelesaian pelaksanaan pengabdian pada Gambar 1, maka Pelatihan pembuatan blog diyakini berdasarkan observasi yang dilaksanakan akan membantu para Guru MA Darul Muttaqin Kota Pagar Alam menjadi pemahaman awal untuk mengikuti era industrialisasi 4.0 pada bidang pendidikan.

\section{HASIL DAN PEMBAHASAN}

3.1. Realisasi \& Pemecahan Masalah

Berdasarkan rangkain pelaksanaan yang dideskripsikan dengan Gambar 1, maka pelaksanaan pelatihan pembuatan blog pembelajaran bagi para Guru MA Darul Muttaqin ini dimulai dengan melakukan pre tes untuk mengetahui tingkat pemahaman para peserta pelatihan pembuatan blog (website) pembelajaran terhadap teknologi dan sistem informasi (TSI) yang berkembang saat ini dan pemanfaatannya terhadap bidang yang ditekuni yaitu pendidikan, yang mana rangkaiannya memenuhi table 1 berikut:

Tabel 1. Rincian Kegiatan Pengabdian (PkM)

\begin{tabular}{|c|c|c|}
\hline No & Jenis Kegiatan & $\begin{array}{c}\text { Penjelasan } \\
\end{array}$ \\
\hline 1 & Pre tes & $\begin{array}{l}\text { Pre tes dilakukan untuk mengetahui tingkat } \\
\text { pemahaman peserta pelatihan terhadap teknologi } \\
\text { blogging (website). }\end{array}$ \\
\hline 2 & Persiapan pembuatan blog & $\begin{array}{l}\text { 1. Melakukan pemeriksaan terhadap PC } \\
\text { (computer/ laptop) dan koneksi internet } \\
\text { karena akan dilakukan pelatihan pembuatan } \\
\text { blog pembelajaran berbasis wordpress. } \\
\text { 2. Pembagian modul pelatihan. }\end{array}$ \\
\hline 3 & $\begin{array}{l}\text { Pelaksanaan pelatihan pembuatan } \\
\text { blog }\end{array}$ & $\begin{array}{l}\text { Narasumber menjelaskan materi pelatihan mulai } \\
\text { dari awal: } \\
\text { 1. Menjelaskan secara umum perkembangan } \\
\text { teknologi dan sistem informasi. } \\
\text { 2. Menjelaskan aplikasi teknologi dan sistem } \\
\text { informasi untuk aplikasi pendidikan. } \\
\text { 3. Mengenalkan blog pada wordpress } \\
\text { 4. Memberikan contoh, aplikasi dan praktek } \\
\text { langsung dengan wordpress pada PC yang } \\
\text { terkoneksi dengan internet, membuat blog } \\
\text { pembelajaran. } \\
\text { 5. Membuat menu-menu tambahan pada blog } \\
\text { pembelajaran yang dibuat agar peserta didik } \\
\text { makin nyaman. } \\
\text { 6. Memberikan tugas dan meminta peserta } \\
\text { pelatihan untuk menyelesaikan permasalahan } \\
\text { yang ditemui saat pembuatan blog. } \\
\text { 7. Mencoba melakukan up load data (materi) } \\
\text { pembelajaran bagi peserta. }\end{array}$ \\
\hline 4 & Pos tes & $\begin{array}{l}\text { Pada akhir pelatihan dilakukan pos tes untuk } \\
\text { mengetahui pemahaman peserta pelatihan } \\
\text { terhadap materi yang diberikan. }\end{array}$ \\
\hline
\end{tabular}

\subsection{Pembahasan \& Hasil}

Pelatihan yang dilakukan di MA Darul Muttaqin ini diikuti oleh 15 Orang guru bidang studi dan pegawai, yang mana berdasarkan Gambar 1 dan Tabel 1 diatas tahap pertama adalah pre 
tes terhadap peserta, yang bertujuan untuk mengetahui pemahaman peserta terhadap teknologi dan sistem informasi (TSI) dan pemahamannya tentang blogging atau website pembelajaran, pertanyaan untuk pre tes ini sebanyak 10 soal, hasilnya seluruh peserta paham akan pentingnya teknologi dan sistem informasi untuk aplikasi pada bidang pendidikan tetapi belum pernah sama sekali mempelajarinya secara langsung, hal ini dapat dilihat pada table 2, dibawah pemahaman peserta hanya pada tahap teori saja, tetapi memiliki semangat untuk mempelajari secara aplikatif, hal ini dibuktikan dengan hasilnya tidak ada peserta yang memperoleh nilai maksimal $(100 \%)$ benar hanya terdapat 2 orang yang memiliki nilai 9 atau hanya $\pm 3 \%$ peserta saja.

Berikutnya pada saat pelatihan antusiasme peserta pelatihan makin meningkat, teknologi dan sistem informasi dengan blog membuat peserta makin bersemangat dan memiliki keinginan yang makin kuat untuk lebih mengetahui pembelajaran dengan menggunakan blog bahkan mereka memiliki niat untuk mengalihkan nantinya blog pembelajaran yang sudah dibuat di subdomain pada website institusinya, semangat para peserta ini menghasilkan pemahaman yang baik dan peningkatan pengetahuan hal ini terbukti pada saat akhir pelatihan, pada saat dilakukan pos tes pengetahuan peserta meningkat sangat jauh bila di banding pada saat pre tes, seperti table dibawah ini.

Tabel 2. Tabel Hasil Pre dan Pos tes

\begin{tabular}{|c|c|c|c|c|c|c|c|}
\hline \multirow{3}{*}{ No } & \multirow{3}{*}{ Komponen } & \multicolumn{6}{|c|}{ Hasil Test } \\
\hline & & \multicolumn{3}{|c|}{ Pre-test } & \multicolumn{3}{|c|}{ Post-test } \\
\hline & & \multicolumn{2}{|c|}{ Jumlah } & $\%$ & \multicolumn{2}{|c|}{ Jumlah } & $\%$ \\
\hline \multirow[t]{7}{*}{1} & \multirow{7}{*}{$\begin{array}{l}\text { Konsep } \\
\text { blogging untuk } \\
\text { mendukung } \\
\text { pembelajaran }\end{array}$} & Benar 10 & 0 & 0 & Benar 10 & 3 & 4.5 \\
\hline & & Benar 9 & 2 & 3 & Benar 9 & 4 & 6 \\
\hline & & Benar 8 & 5 & 6.5 & Benar 8 & 4 & 6 \\
\hline & & Benar 7 & 3 & 4.5 & Benar 7 & 2 & 3 \\
\hline & & Benar 6 & 2 & 3 & Benar 6 & 2 & 3 \\
\hline & & Benar 5 & 2 & 3 & Benar 5 & 0 & 0 \\
\hline & & Benar 4 & 1 & 1.5 & Benar 4 & 0 & 0 \\
\hline
\end{tabular}

Peningkatan begitu signifikan yang mana pada saat sebelum dilaksanakan pelatihan ini pemahaman peserta terhadap teori dan aplikasi tidak maksimal tetapi setelah dilakukan pelatihan peningkatannya sangat signifikan sekali, terlihat yang mendapat nilai 10 sebesar $4,5 \%$ dari total peserta yang mengikuti pelatihan, bahkan yang mencapai nilai Sembilan meningkat lebih besar yaitu sebanyak $6 \%$ dari jumlah peserta.

\section{KESIMPULAN}

Maka berdasarkan dari pembahasan dan hasil yang dicapai dari pelaksanaan pelatihan ini dapat diperoleh kesimpulan sebagai berikut:

a. Peningkatan pemahaman peserta pelatihan yang sangat baik.

b. Bertambahnya pemahaman peserta terhadap teknologi dan sistem informasi

c. Perlu ada pelatihan yang berkesinambungan.

\section{SARAN}

Saran-saran untuk untuk penelitian lebih lanjut untuk menutup kekurangan penelitian. Tidak memuat saran-saran diluar untuk penelitian lanjut.

\section{UCAPAN TERIMA KASIH}

Penulis mengucapkan terima kasih kepada Panitia KKN dan Pengabdian bagi Dosen, terima kasih kepada keluarga, kawan-kawan dosen. 


\section{DAFTAR PUSTAKA}

[1] Arif, A., \& Mukti, Y. (2017). Rancang Bangun Website Sekolah Menengah Pertama (SMP) Negeri 8 Kota Pagar Alam. JURNAL ILMIAH BETRIK: Besemah Teknologi Informasi dan Komputer, 8(03), 156-165.

[2] Muslim, B. 2018. Pelatihan aplikasi editing video dengan filmora., Laporan Pengabdian Kepada Masyarakat, LPPM STT Pagaralam.

[3] Muslim, B. (2017). Pengantar Teknologi informasi Teknik Informatika. Yogyakarta: C.V BUDI UTAMA (Deepublish) Yogyakarta.

[4] Muslim, B. (2018). Analisis system informasi (SI) terintegrasi di Perguruan Tinggi (PT) (Studi Kasus: STT Pagaralam). Jurnal Teknologi Informasi MURA, Vol 10. Page 83-91.

[5] Muslim, B (2017). Sistem Pakar Diagnosa Awal Penyakit Ginjal Berbasis Web Menggunakan PHP Dan MySQL (Studi Kasus: RSUD Besemah Kota Pagar Alam). JURNAL BETRIK, LPPM STTP, Vol 12, Pp 115-122.

[6] Hutchinson E. Sarah and Sawyer C. Stacey, 2000, Computers, Communications \& Information, McGraw Hill Companies Inc.

[7] Indonesia Services Education HP Tim, 2001, Manajemen Sistem Belajar Di Dunia Maya, Majalah Info Komputer.

[8] Jeffcoate Judith, 1995, Multimedia In PracticeTechnology and Applications, Prentice Hall International (UK) Limited.

[9] Long Larry and Long Nancy, 2000, Computers 7th Edition, Prentice-Hall Inc.

[10] M.H Jogiyanto, 1995, Pengenalan Komputer, Andi Offset Yogyakarta.

[11] Horsley, M., Knight, B., \& Huntly, H. 2010. The role of textbooks and other teaching and learning resources in higher education in Australia: Change and continuity in supporting learning. IARTEM 1-Journal. 3(2). 43-61.Sadiman, A.vS., Rahardjo, R., Haryono, A., \& R

[12] ahardjito. 2006. Media pendidikan: Pengertian, pengembangan, dan pemanfaatan. Jakarta: Rajagrafindo Persada.

[13] Purnomo, W. 2008. Pembelajaran berbasis ICT. Makalah. Disajikan pada workshop pembelajaran berbasis ICT di Dinas Pendidikan Provinsi Sulawesi Selatan , 11-14 Agustus 2008.

[14] Arsyad, A. 2009. Media pembelajaran. Jakarta: Rajagrafindo Persada.

[15] Joshi, M., Chugh, R. 2009. New paradigms in the teaching and learning of accounting: Use of educational blogs for reflective thinking. International Journal of Education and Development using Information and Communication Technology. 5 (3) 6-18.

[16] Muslim, B \& Prasetio, Y. 2017. Sistem Informasi Penerimaan Siswa Baru SMP Xaverius Pagaralam Berbasis Website. JUTIM (Jurnal Teknik Informatika Musirawas) 2 (2), 90-98

[17] Isro'Mukti, Y. (2017). Sistem Informasi Madrasah Aliyah Negeri Pagar Alam Berbasis Web. Indonesian Journal of Computer Science, 6(2), 192-205.

[18] Mukti, Y. (2017). Perencanaan Strategis Sistem Informasi Dan Teknologi Informasi Pada Sekolah Menengah Kejuruan Negeri 2 Pagar Alam. JURNAL ILMIAH BETRIK: Besemah Teknologi Informasi dan Komputer, 8(02), 83-92.

[19] Isro'Mukti, Y. (2018, October). Sistem Informasi Manajemen Aset Sekolah Tinggi Teknologi Pagaralam Berbasis Web. In Seminar Nasional Teknologi Informasi dan Komunikasi (SEMNASTIK) (Vol. 1, No. 1, pp. 632-638).

[20] Mukti, Y. (2018). Rancang Bangun Website Sekolah Dengan Metode User Centered Design (UCD). JURNAL ILMIAH BETRIK: Besemah Teknologi Informasi dan Komputer, 9(02), 84-95. 